Article

\title{
Safety Concept for Textile-Reinforced Concrete Structures with Bending Load
}

\author{
Sergej Rempel ${ }^{1, *}$, Marcus Ricker ${ }^{2}$ and Josef Hegger ${ }^{3}$ \\ 1 Hochschule Augsburg, University of Applied Sciences, An der Hochschule 1, 86161 Augsburg, Germany \\ 2 Institute of Structural Engineering, Hochschule Biberach University of Applied Sciences, Karlstraße 11, \\ 88400 Biberach, Germany; ricker@hochschule-bc.de \\ 3 Institute of Structural Concrete, RWTH Aachen University, Mies-van-der-Rohe-Straße 1, \\ 52074 Aachen, Germany; jhegger@imb.rwth-aachen.de \\ * Correspondence: sergej.rempel@hs-augsburg.de; Tel.: +49-821-5586-3637
}

Received: 14 September 2020; Accepted: 7 October 2020; Published: 20 October 2020

check for updates

\begin{abstract}
In most countries, for the production and execution of concrete structures with textile reinforcement, building owners must have a general approval (e.g., "abZ" in Germany) or an individual license (e.g., "ZiE" in Germany). Therefore, it is quite common for building authorities to request experimental tests that evaluate the ultimate limit state (ULS) and the serviceability limit state (SLS). However, these experimental tests are detailed, time-consuming and expensive. A practical and simple design model would help to reduce the number of tests needed and would offer structural planners a useful tool. An important aspect is that such design model must fulfil a set of reliability requirements in order to guarantee an adequate safety standard. To this end, probabilistic calculations are required. For the setup of such model, different parameters must be considered, namely the effective depth $d$ and the tensile failure stress of the textile $f_{\mathrm{t}}$ for the concrete compressive strength $f_{\mathrm{c}}$. This article presents the probabilistic calculations needed to attain a general safety factor $\gamma_{\mathrm{T}}$ that satisfies all the safety requirements for the textile reinforcement of concrete structures with bending load.
\end{abstract}

Keywords: carbon concrete; textile-reinforced concrete; bending load; safety concept; safety factor

\section{Introduction and Objective}

Textile-reinforced concrete (TRC) is an innovative composite material that uses mesh-like reinforcements made of alkali-resistant glass (AR-glass) or carbon. In contrast to ordinary steel reinforcements, the textile reinforcements do not corrode. As a result, the concrete cover can be minimized, which leads to extremely thin and slender concrete constructions. The latest developments show that, due to the higher tensile strength and the higher elastic modulus, carbon filaments are used more often to realize constructions. As a consequence, the new name "carbon concrete" has appeared [1-3].

This paper aims to determine a general partial safety factor $\gamma_{\mathrm{T}}$ for the textile reinforcement of concrete structures with bending load through the calculation of a probability of failure $p_{\mathrm{f}}$ (or the corresponding reliability index $\beta$ ). Several researchers have studied the bending capacity of textile-reinforced concrete members $[4,5]$. However, in the design of bending reinforcement of textile-reinforced members, the partial safety factors for the textile reinforcement have not been analyzed in detail.

The bending load capacity depends on different parameters such as the ultimate tensile strength of the textile reinforcement $f_{\mathrm{t}}$ or the concrete compressive strength $f_{\mathrm{c}}$. These parameters vary according to the application field and, therefore, have a direct influence on the resulting reliability index $\beta$. 
This influence can be determined through sensitivity factors $\alpha_{\mathrm{i}}$, that can be selectively considered to increase the safety level of the structural element being analyzed. Furthermore, the partial safety factor $\gamma_{\mathrm{T}}$ can vary within the reliability analysis in order to attain the desired reliability index $\beta$.

The results of the reliability analysis depend on the probability distribution allocated to the variable parameters. The more realistically the probability distributions are estimated, the more accurate are the respective probabilities of failure. In some cases, such as for the textile ultimate strength $f_{\mathrm{t}}$, the probability distributions can be determined with acceptable effort. Other distributions, especially on the impact side, tend to be more complex to determine. Various models can be found in the literature, but they differ considerably $[6,7]$.

For the reliability analysis, the first-order reliability method (FORM), the Monte Carlo method (MC) and the Monte Carlo method with importance sampling (MC-IS) were used. The calculations were performed with the software Maple [8].

In this paper, all the varying parameters are listed; however, the influence of the relevant parameters is illustrated with selected results. Further results of the parameter calculations can be found in [9]. The abbreviations and symbols used in this study are also described in detail in [9]. The results of this paper were originally published in German [10].

\section{Boundary Conditions}

\subsection{General}

For the reliability analysis, the input parameters were defined. Firstly, the static system and its boundary conditions were determined. Secondly, the design model needed for the calculation of the load-bearing capacity was selected. Finally, all the input parameters were described through stochastic models. The calculated probabilities of failure (or reliability indices $\beta$ ) are only valid for the analysis of selected boundary conditions. Thus, for a general valid statement, extensive parametric studies are needed.

\subsection{Static System and Geometric Dimensions}

In this study, a single-span beam with length $l$ loaded with a dead load $g$ and a live load $q$ is examined (Figure 1). The cross-section of the beam is rectangular with dimensions $b \times h$ (width $x$ height). Furthermore, the distance from the extreme compression fiber to the centroid of the longitudinal tensile reinforcement (effective depth) $d$ and the reinforcement cross-sectional area $A_{\mathrm{t}}$ are specified. Table 1 lists the statistical parameters of the geometric dimensions and Table 2 lists the statistical parameters of the effects.
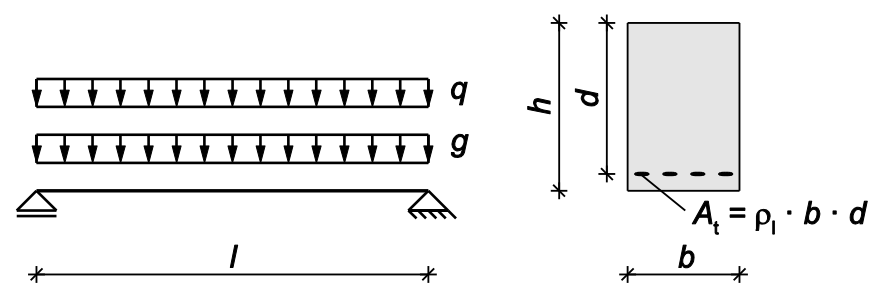

Figure 1. Structural system and dimensions of rectangular cross-section. 
Table 1. Overview of the geometric dimensions—statistical description of the basic variables [9].

\begin{tabular}{cccccc}
\hline Parameter $^{\mathbf{1}}$ & Description & DT $^{2}$ & Unit & $\mu_{\mathbf{X}}{ }^{3}$ & $\sigma_{\mathbf{X}}{ }^{4}$ \\
\hline$d_{\mathrm{I}}$ & effective depth & ND & $(\mathrm{mm})$ & 15 & 2 \\
\hline$d_{\mathrm{II}}$ & effective depth & ND & $(\mathrm{mm})$ & 60 & 3 \\
\hline$h_{\mathrm{I}}$ & height & det. & $(\mathrm{mm})$ & 30 & - \\
\hline$h_{\mathrm{II}}$ & height & det. & $(\mathrm{mm})$ & 80 & - \\
\hline$B$ & width & det. & $(\mathrm{mm})$ & 1000 & - \\
\hline$L$ & span & det. & $(\mathrm{mm})$ & 1000 & - \\
\hline$\rho_{\mathrm{l}}$ & $\begin{array}{c}\text { reinforcement } \\
\text { ratio }\end{array}$ & varies & $(-)$ & - & - \\
\hline
\end{tabular}

\footnotetext{
${ }^{1}$ Basic variable; ${ }^{2}$ distribution type: ND = normally distributed, det. = deterministic value; ${ }^{3}$ expected value of the basic variable $X ;{ }^{4}$ standard deviation of the basic variable $X$.
}

Figure 1 shows the parameters that have an influence on the bending load capacity, namely $g, q$, $l, h, d, b$ and $A_{\mathrm{t}}$. Two different effective depths $d$ are examined in the reliability calculations: $d_{\mathrm{I}}=15$ $\mathrm{mm}$ and $d_{\mathrm{II}}=60 \mathrm{~mm}$. Both values are commonly used in carbon concrete constructions. Examples for the variation of effective depths $d$ can be found on curtain façades and pedestrian bridges realized with AR-glass or carbon reinforcement [11-18]. The corresponding component heights $h_{\mathrm{I}}$ and $h_{\mathrm{II}}$ are regarded as deterministic due to their low impact on the probability of failure; therefore, they are not random variables (i.e., scattering values). The same applies to the width $b$ and the span $l$. In order to investigate textile failure and concrete failure, the reinforcement ratio $\rho_{1}$ varies within the reliability analysis.

Table 2. Overview of the loads—statistical description of the applied loads [9].

\begin{tabular}{cccccccc}
\hline Parameter & Description & DT $^{\mathbf{1}}$ & Unit & Char. Value & $\mu_{\mathbf{x}}$ & $\sigma_{\mathbf{x}}$ & $\boldsymbol{v}_{\mathbf{x}}$ \\
\hline$G$ & dead loads [19] & ND & $\left(\mathrm{N} / \mathrm{mm}^{2}\right)$ & $g_{\mathrm{k}}$ & $g_{\mathrm{k}}$ & $0.1 g_{\mathrm{k}}$ & 0.1 \\
\hline$Q$ & live loads [19] & Ext. I & $\left(\mathrm{N} / \mathrm{mm}^{2}\right)$ & $q_{\mathrm{k}}$ & $0.7 q_{\mathrm{k}}$ & $0.14 q_{\mathrm{k}}$ & 0.2 \\
\hline$\eta_{1}$ & load ratio $g / q$ & det. & $(-)$ & - & 0.5 & - & - \\
\hline$\eta_{2}$ & load ratio $g / q$ & det. & $(-)$ & - & 1.0 & - & - \\
\hline \multicolumn{7}{c}{ Distribution type: Ext I = generalized extreme value distribution type-I (Gumbel distribution). }
\end{tabular}

The statistical properties of live loads $q$ were taken from the literature $[19,20]$. In contrast to steel-reinforced concrete, textile-reinforced components can be slimmer due to the corrosion-resistant reinforcement so that the typical load ratio of dead and live loads $\eta$ changes. The amount of $q$ in the total load increases due to the lower dead load. An example is the first pedestrian bridge made of carbon concrete in Ebingen [17], where the dead load of the construction is approximately $140 \mathrm{kN}$ and the traffic loads are about $240 \mathrm{kN}$. Since the traffic loads are roughly double than the value of the permanent load, $\eta_{1}$ is close to 0.5 . For comparison, the typical load ratio for steel-reinforced concrete components has a $\eta_{2}$ value approximately equal to 1.0. Both ratios were used in the calculations.

\subsection{Design Model}

For the verification of the ultimate limit state, the bending load capacity $M_{\mathrm{Rd}}$ should, at least, be equal to the applied design moment $M_{\mathrm{Ed}}$ (Equation (1)). The calculation of $M_{\mathrm{Ed}}$ for the specified static system (Figure 1) is carried out according to Equation (2).

$$
\begin{gathered}
M_{E d} \leq M_{R d} \\
M_{E d}=\gamma_{G} \frac{g_{k} l^{2}}{8}+\gamma_{G} \frac{q_{k} l^{2}}{8}
\end{gathered}
$$


The values for the partial safety factors $\gamma_{\mathrm{G}}$ and $\gamma_{\mathrm{Q}}$ are taken from EN 1990 [21] and are summarized in Table 3.

Table 3. Overview of the safety elements for the impact side.

\begin{tabular}{cccc}
\hline Parameter & Description & Unit & Value \\
\hline$\gamma_{\mathrm{G}}$ & dead load & $(-)$ & 1.35 \\
\hline$\gamma_{\mathrm{Q}}$ & variable load & $(-)$ & 1.5 \\
\hline
\end{tabular}

The bending load capacity $M_{R d}$ is obtained by applying a linear stress-strain curve for the concrete with Equation (3) for a textile failure and with Equation (4) for a concrete failure. The type of failure can be verified with Equation (5).

$$
\begin{gathered}
M_{R d}=F_{t d} z=A_{t} f_{t d \cdot}\left(d-\frac{\frac{\alpha_{e d} A_{t}}{b}\left[-1+\sqrt{1+\frac{2 b d}{\alpha_{e d} A_{t}}}\right]}{3}\right) \\
M_{R d}=F_{c d} z=f_{c d} \cdot \frac{\alpha_{e d} A_{t}\left[-1+\sqrt{1+\frac{2 b d}{\alpha_{e d} A_{t}}}\right]}{2}\left(d-\frac{\frac{\alpha_{e d} A_{t}}{b}\left[-1+\sqrt{1+\frac{2 b d}{\alpha_{e d} A_{t}}}\right]}{3}\right) \\
\sigma_{c}=\frac{F_{t d} 2}{b x}=\frac{A_{t} f_{t d} 2}{\alpha_{e d} A_{t}\left[-1+\sqrt{1+\frac{2 b d}{\alpha_{e d} A_{t}}}\right]} \leq f_{c d}
\end{gathered}
$$

Both equations depend on the relation $\alpha_{\mathrm{Ed}}$ between the elastic modulus of the concrete $E_{\mathrm{cd}}$ and the textile reinforcement $E_{\mathrm{tm}}$. Figures 2 and 3 illustrate both elastic modulus and Equation (6) expresses the relation between them.

$$
\alpha_{e d}=\frac{E_{t m}}{E_{c d}}
$$

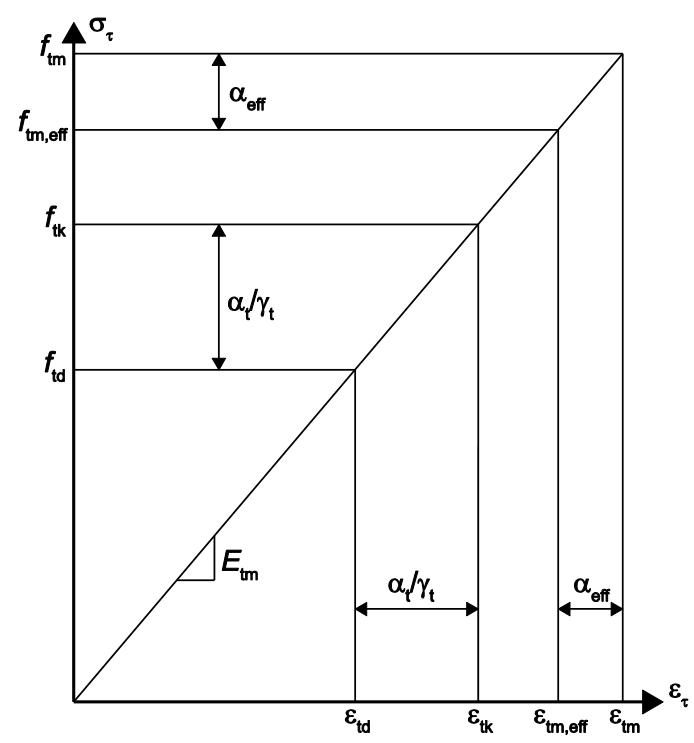

Figure 2. $\sigma-\varepsilon$ diagram of the reinforcement for the design. 


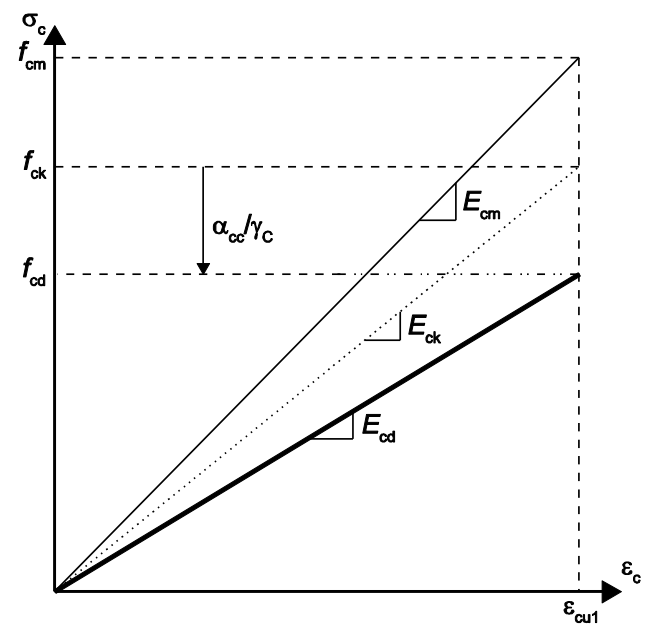

(a)

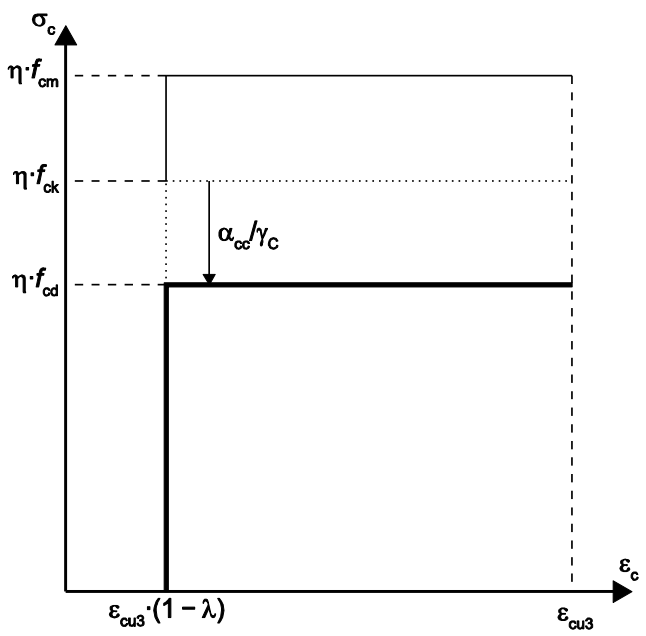

(b)

Figure 3. $\sigma-\varepsilon$ diagram for the concrete: (a) linear elastic-strain curve and (b) stress block.

Furthermore, the closed solution for a rectangular stress-strain curve for the concrete is also taken into account for the assessment of the bending load capacity $M_{\mathrm{Rd}}$. Equation (7) is used for a textile failure, whereas Equation (8) is adopted for a concrete failure. The type of failure is verified by means of the balanced reinforcement ratio $\rho_{1}$ (Equation (9)). The procedures are described in detail in [9].

$$
\begin{gathered}
M_{R d}=\rho_{l} b d^{2} f_{t d}\left(1-\frac{\rho_{l} f_{t d}}{2 \eta f_{c d}}\right) \\
M_{R d}=\eta f_{c d} b \lambda \xi d^{2}\left(1-\frac{\lambda \xi}{2}\right) \\
\rho_{l}<\rho_{b d}=\frac{f_{c d}}{f_{t d}} \frac{\varepsilon_{c u 3}}{\varepsilon_{t d}+\varepsilon_{c u 3}} \eta \lambda
\end{gathered}
$$

In addition, the model uncertainties have to be considered both on the action side $\theta_{\mathrm{E}}$ and on the resistance side $\theta_{\mathrm{R}}$ (refer to Table 4). The stochastic parameters adopted for the model uncertainties were taken from $[9,19]$.

Table 4. Overview of the model uncertainty—statistical description of the variables [9].

\begin{tabular}{cccccccc}
\hline Parameter & Description & DT $^{\mathbf{1}}$ & Unit & Char. Value & $\mu_{\mathbf{x}}$ & $\sigma_{\mathbf{x}}$ & $\boldsymbol{v}_{\mathbf{x}}$ \\
\hline$\theta_{\mathrm{E}}$ & action & LN & $(-)$ & $(-)$ & 1.0 & $(-)$ & 0.1 \\
\hline$\theta_{\mathrm{R}}$ & resistance & LN & $(-)$ & $(-)$ & 1.0 & $(-)$ & 0.1 \\
\hline \multicolumn{7}{c}{ Distribution type: $\mathrm{LN}=$ lognormal distribution. } \\
\end{tabular}

\subsection{Material Characteristics}

Normally, reliability calculations require knowledge of the statistical properties of materials and their constitutive equations. In this study, relevant results of $[22,23]$ are used, which are shown in Figures 2 and 3.

For the reinforcement, a linear elastic stress-strain curve is applied, which is determined by means of the standardized fiber strand tensile test [22] (Figure 2). The mean value of the calculated ultimate tensile strength $f_{\mathrm{tm}}$ is reduced to the effective ultimate tensile strength $f_{\mathrm{tm} \text {,eff }}$ with a reduction factor $\alpha_{\text {eff }}$ equal to 0.85 . This reduction occurs due to the influences of the number and length of fiber strands in the real component compared to the individual fiber strands tested [22]. With the reduced ultimate tensile strength $f_{\mathrm{tm}, \text { eff }}$, the characteristic ultimate tensile strength $f_{\mathrm{tk}}$ and the design tensile 
strength $f_{\text {td }}$ are determined by taking into account the partial safety factor $\gamma_{\mathrm{T}}$ and the reduction factor $\alpha_{\mathrm{t}}$. This factor includes the durability of AR-glass and carbon filaments in a concrete environment (Figure 6). For the concrete, a linear elastic stress-strain curve and a stress block were applied (Figure 3). The corresponding values for the strains $\varepsilon_{\mathrm{cu} 1}$ and $\varepsilon_{\mathrm{cu} 3}$ as well as the coefficients $\lambda$ and $\eta$ were taken from EN 1992-1-1 [24].

Table 5 shows the statistical properties used for the two basic variables concrete compressive strength $f_{\mathrm{cm}}$ and ultimate compression strain of concrete $\varepsilon_{\mathrm{cu}}$. Two strength classes were considered, as these are frequently used in the manufacture of textile concrete components.

Table 5. Overview of the concrete properties-description of the stochastic model for the basic variables.

\begin{tabular}{cccccccc}
\hline Parameter & Description & DT & Unit & Char. Value & $\mu_{\boldsymbol{X}}$ & $\sigma_{\boldsymbol{X}}$ & $\boldsymbol{v}_{\boldsymbol{X}}$ \\
\hline$f_{c, 50}$ & $\mathrm{C} 50 / 60$ & $\mathrm{LN}$ & $\left(\mathrm{N} / \mathrm{mm}^{2}\right)$ & 50 & 58 & 5 & 0.09 \\
\hline$f_{c, 90}$ & $\mathrm{C} 90 / 105$ & $\mathrm{LN}$ & $\left(\mathrm{N} / \mathrm{mm}^{2}\right)$ & 90 & 98 & 5 & 0.05 \\
\hline$\varepsilon_{c u 1,50}$ & $\mathrm{C} 50 / 60$ & $\mathrm{LN}$ & $(\% \mathrm{oo})$ & $(-)$ & 3.5 & $(-)$ & 0.15 \\
\hline$\varepsilon_{c u 1,90}$ & $\mathrm{C} 90 / 105$ & $\mathrm{LN}$ & $(\% \mathrm{o})$ & $(-)$ & 2.8 & $(-)$ & 0.15 \\
\hline$\varepsilon_{c u 3,50}$ & $\mathrm{C} 50 / 60$ & $\mathrm{LN}$ & $(\% \mathrm{o})$ & $(-)$ & 3.5 & $(-)$ & 0.15 \\
\hline$\varepsilon_{c u 3,90}$ & $\mathrm{C} 90 / 105$ & $\mathrm{LN}$ & $(\%)$ & $(-)$ & 2.6 & $(-)$ & 0.15 \\
\hline \multirow{2}{*}{$\alpha_{c c}$} & $\begin{array}{c}\text { permanent } \\
\text { concrete }\end{array}$ & det & $(-)$ & $(-)$ & 0.85 & $(-)$ & $(-)$ \\
\hline
\end{tabular}

A partial safety factor $\gamma_{C}$ equal to 1.5 was applied, as recommended in EN 1992-1-1 [24]. The characteristic values of the two basic variables for the textiles made of carbon and AR-glass -tensile strength $f_{\mathrm{t}}$ and Young's modulus $E_{\mathrm{t}}$-are summarized in Table 6. In addition, two types of textile reinforcement made of AR-glass and carbon were considered in the reliability calculation. To take into account the limited durability of the AR-glass textile, the value of $\alpha_{\mathrm{t}, \mathrm{A}}$ equal to 0.6 was used. A smaller reduction factor $\alpha_{\mathrm{t}, \mathrm{C}}$ equal to 0.9 was selected for the carbon reinforcement [25]. In order to quantify the influence of durability on the safety level, the calculations were repeated without reduction by assuming that $\alpha_{\mathrm{t}, \mathrm{A}}$ is equal to 1.0 or $\alpha_{\mathrm{t}, \mathrm{C}}$ is equal to 1.0 for both types of reinforcement.

Table 6. Overview of the textile properties-description of the stochastic model for the basic variables.

\begin{tabular}{cccccccc}
\hline Parameter & Description & DT & Unit & Char. Value & $\mu_{\mathbf{X}}$ & $\sigma_{\mathbf{X}}$ & $\boldsymbol{v}_{\mathbf{X}}$ \\
\hline$f_{t, A}$ & AR-glass & ND & $\left(\mathrm{N} / \mathrm{mm}^{2}\right)$ & 1150 & 1300 & 91 & 0.07 \\
\hline$f_{t, C}$ & carbon & ND & $\left(\mathrm{N} / \mathrm{mm}^{2}\right)$ & 2345 & 2700 & 216 & 0.08 \\
\hline$E_{t, A}$ & AR-glass & ND & $\left(\mathrm{N} / \mathrm{mm}^{2}\right)$ & $(-)$ & 75,000 & 750 & 0.01 \\
\hline$E_{t, C}$ & carbon & ND & $\left(\mathrm{N} / \mathrm{mm}^{2}\right)$ & $(-)$ & 240,000 & 2400 & 0.01 \\
\hline$\alpha_{t, A}$ & AR-glass & $\operatorname{det}$ & $(-)$ & $(-)$ & 0.6 & $(-)$ & $(-)$ \\
\hline$\alpha_{t, C}$ & carbon & $\operatorname{det}$ & $(-)$ & $(-)$ & 0.9 & $(-)$ & $(-)$ \\
\hline$\alpha_{t}$ & AR-glass/carbon & $\operatorname{det}$ & $(-)$ & $(-)$ & 1.0 & $(-)$ & $(-)$ \\
\hline
\end{tabular}

\section{Limit State Functions}

The fully probabilistic calculation for concrete was carried out considering a linear stress-strain curve. For a textile failure, the limit state is expressed through Equation (10). The validity can be 
evaluated with Equation (11). If it cannot be fulfilled, a concrete failure occurs, and the limit state expressed through Equation (12) should be used.

$$
\begin{gathered}
0=\theta_{R}\left[A_{t} f_{t m} \alpha_{t}\left(d-\frac{\frac{\alpha_{E} A_{t}}{b}\left[-1+\sqrt{1+\frac{2 b d}{\alpha_{E} A_{t}}}\right]}{3}\right]\right)-\theta_{E}\left[\frac{g l_{2}}{8}+\frac{q l_{2}}{8}\right] \\
\sigma_{c}=\frac{F_{t u} 2}{b x}=\frac{A_{t} f_{t m} 2 \alpha_{t}}{b\left(\frac{\alpha_{E} A_{t}}{b}\left[-1+\sqrt{1+\frac{2 b d}{\alpha_{E} A_{t}}}\right)\right.} \leq f_{c m} \\
\left.0=\theta_{R}\left[f_{c m} b \frac{\frac{\alpha_{E} A_{t}}{b}\left[-1+\sqrt{1+\frac{2 b d}{\alpha_{E} A_{t}}}\right]}{2}\right] d-\frac{\frac{\alpha_{E} A_{t}}{b}\left[-1+\sqrt{1+\frac{2 b d}{\alpha_{E} A_{t}}}\right]}{3}\right]-\theta_{E}\left[\frac{g l_{2}}{8}+\frac{q l_{2}}{8}\right]
\end{gathered}
$$

If a rectangular stress-strain curve is applied for the concrete, the limit state is expressed through Equation (13). If a concrete failure occurs, the limit state expressed through Equation (14) has to be taken into account. The type of failure is evaluated with Equation (15). The height of the compression zone can be calculated according to Equation (16).

$$
\begin{aligned}
& 0=\theta_{R}\left[\rho_{l} b d^{2} f_{t m}\left(1-\frac{\rho_{l} f_{t m}}{2 \eta f_{c m}}\right)\right]-\theta_{E} \times\left[\frac{g l_{2}}{8}+\frac{q l_{2}}{8}\right] \\
& 0=\theta_{R}\left[\eta f_{c m} b \lambda \xi d^{2}\left(1-\frac{\lambda \xi}{2}\right)\right]-\theta_{E}\left[\frac{g l_{2}}{8}+\frac{q l_{2}}{8}\right] \\
& \rho_{l}<\rho_{b}=\frac{f_{c m}}{f_{t m, e f f}} \frac{\varepsilon_{c u 3}}{\varepsilon_{t m, e f f}+\varepsilon_{c u 3}} \eta \lambda \\
& \xi=\frac{x}{d}=\frac{\sqrt{\frac{E_{t m} \varepsilon_{c u 3}}{\eta f_{c m} \lambda}} \sqrt{\frac{E_{t m} \varepsilon_{c u}}{\eta f_{c m} \lambda} \rho_{l}+4} \sqrt{\rho_{l}}}{2}-\frac{\frac{E_{t m} \varepsilon_{c u}}{\eta f_{c m} \lambda} \rho_{l}}{2}
\end{aligned}
$$

\section{Procedure of Reliability Calculation}

At the beginning of the reliability analysis, the boundary conditions should be defined in order to, subsequently, determine the bending load capacity $M_{\mathrm{Rd}}$ in the design model. To this end, the case distinction between concrete and textile failure shall be taken into account. The decisive $M_{R d}$ also defines the allowable load action due to equilibrium. For the fully probabilistic analysis, the maximum loads $q_{\mathrm{k}}$ and $g_{\mathrm{k}}$ can be determined in the last step. The calculation procedure for the assumption of a linear stress-strain curve for the concrete is shown in Figure 4.

After the design, all the parameters for the reliability calculation are defined and the probability of failure can be determined through the methods FORM and Monte Carlo integration with and without importance sampling (IS). The flowcharts for the different methods are summarized in Figures 5 and 6. Detailed descriptions of these methods can be found in [19,20,26-28]. 


\begin{tabular}{|c|c|c|c|}
\hline \multicolumn{4}{|c|}{ Define boundary conditions } \\
\hline $\begin{array}{l}\text { Geometric } \\
\text { conditions } \\
w, d, h, l, \rho_{\mathrm{I}}\end{array}$ & $\begin{array}{c}\text { Partial safety } \\
\text { factors } \\
\gamma_{G}, \gamma_{Q}, \gamma_{T}, \gamma_{C}\end{array}$ & $\begin{array}{c}\text { Material } \\
\text { properties } \\
f_{\mathrm{tm}}, \mathrm{E}_{\mathrm{tm}}, \alpha_{\mathrm{t}}, \\
f_{\mathrm{cm}}, \varepsilon_{\mathrm{cu} 1}, \alpha_{\mathrm{cc}}\end{array}$ & $\begin{array}{c}\text { Other } \\
\text { parameters } \\
\theta_{E}, \theta_{R}, \eta\end{array}$ \\
\hline \multicolumn{4}{|c|}{ Calculate $\mathrm{M}_{\mathrm{Rd}}$} \\
\hline \multicolumn{2}{|c|}{$\begin{array}{l}\text { Case: Textile failure } \\
\text { (equation (3)) }\end{array}$} & \multicolumn{2}{|c|}{ Checking } \\
\hline (equati & n (3)) & \multicolumn{2}{|c|}{$\begin{array}{c}\text { Concrete failure } \\
\text { (equation (4)) }\end{array}$} \\
\hline \multicolumn{2}{|c|}{ Calculate $\mathrm{M}_{\mathrm{Rd}}$} & \multirow[b]{3}{*}{ 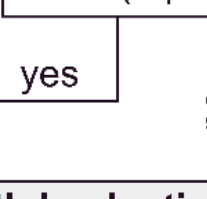 } & \multirow[b]{2}{*}{ I } \\
\hline $\begin{array}{l}\text { Case: Conc } \\
\text { (equati }\end{array}$ & $\begin{array}{l}\text { rete failure } \\
\text { on (5)) }\end{array}$ & & \\
\hline \multicolumn{3}{|c|}{ Calculate $g_{k}$ and $q_{k}$ with load ratio $\eta$} & \\
\hline \multicolumn{3}{|c|}{$M_{\mathrm{Rd}}=M_{\mathrm{Ed}}=\gamma_{\mathrm{G}}\left(g_{\mathrm{k}}{ }^{2}\right) / 8+\gamma_{\mathrm{Q}}\left(q_{\mathrm{k}}{ }^{2}\right) / 8$} & $=g_{k} / q_{k}$ \\
\hline \multicolumn{4}{|c|}{$\frac{\downarrow}{\not \text { Reliability calculation }}$} \\
\hline FORM & Monte & Sarlo & nte Carlo IS \\
\hline
\end{tabular}

Figure 4. Flowchart for the calculation of $M_{\mathrm{Rd}}$ and $M_{\mathrm{Ed}}$ under the assumption of a linear $\sigma-\varepsilon$ diagram for the concrete.

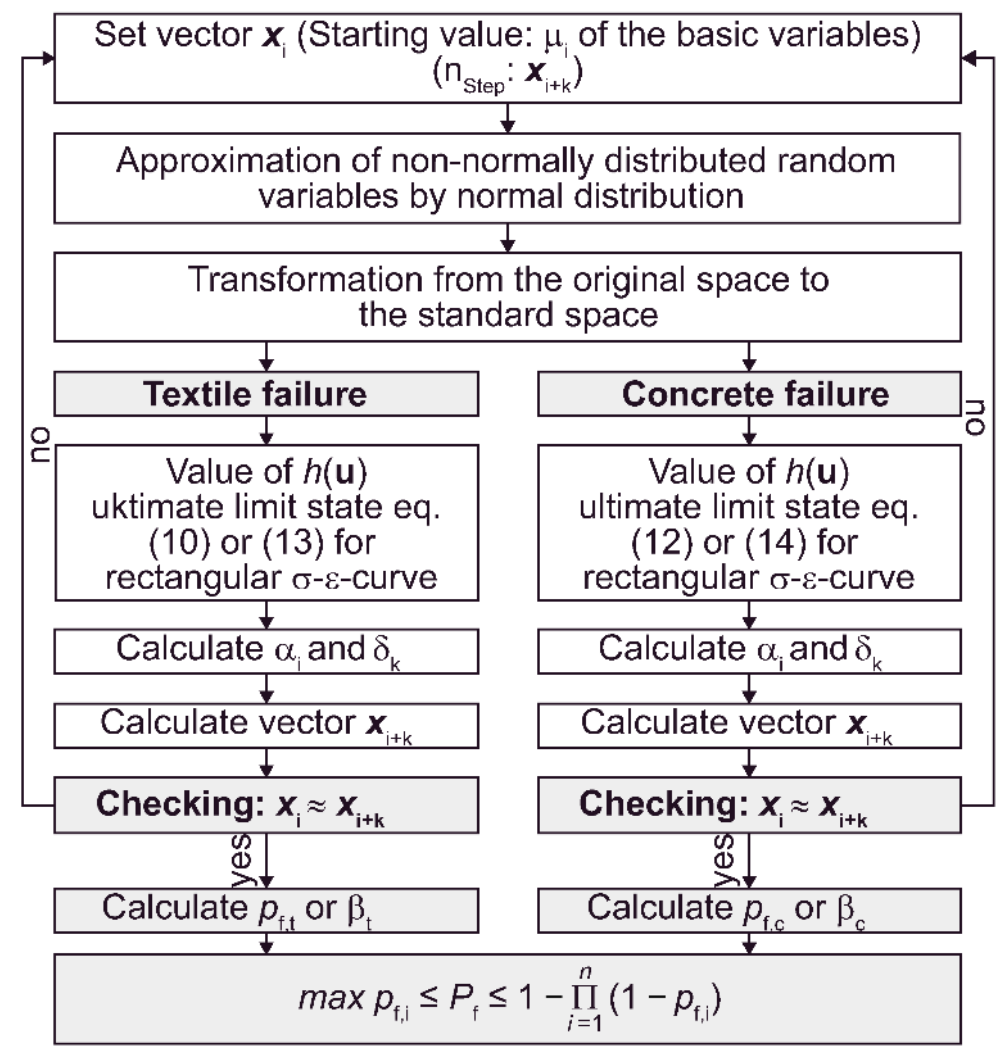

Figure 5. Flowchart for the calculation of the failure probability according to first-order reliability method (FORM) under the assumption of a linear $\sigma-\varepsilon$ diagram for the concrete. 


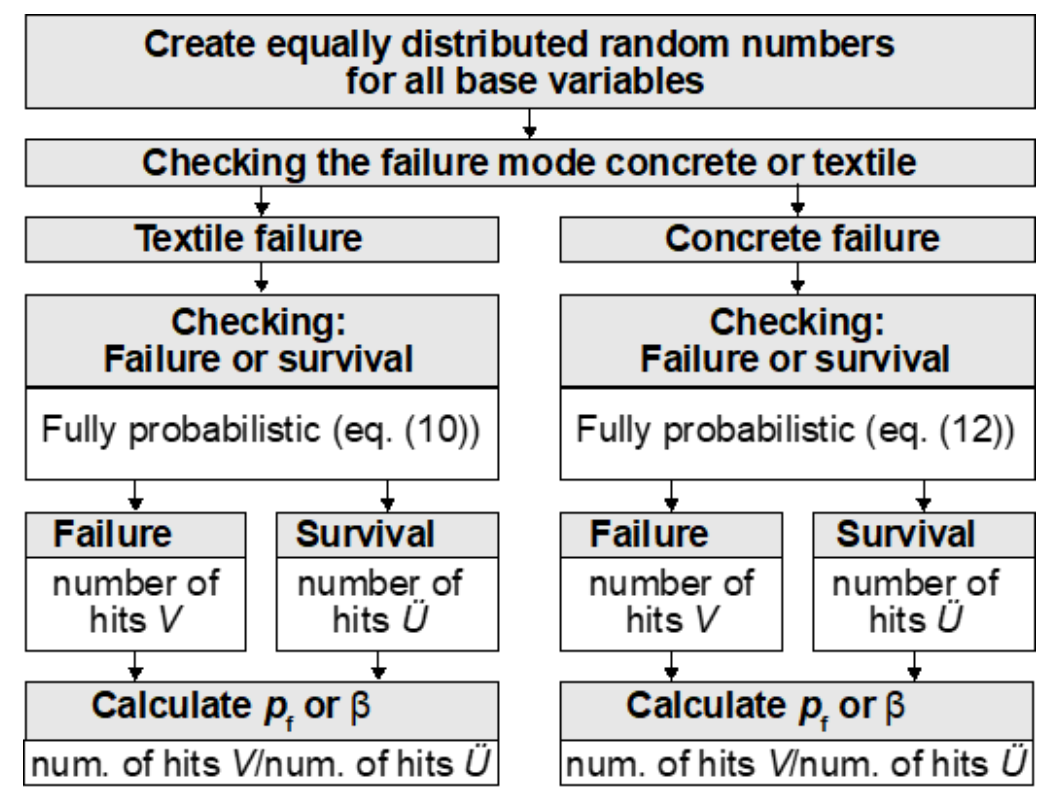

Figure 6. Flowchart for the calculation of the failure probability according to the Monte Carlo method.

\section{Reliability Calculation Results}

\subsection{General Observations}

The reliability index $\beta$ is given as a function of the reinforcement ratio $\rho_{1}$ and the effective depth $d$. The partial safety factors $\gamma_{\mathrm{T}}$ vary between 1.0 and 1.5 so that the required safety level can be easily identified. To this end, the level at which these factors lead to a target reliability index $\beta$ equal to 3.8 was determined, considering a reference period of 50 years.

Figure 7 symbolically illustrates the results of the parametric studies. The curve in Figure 7 is divided into three states: $\mathrm{A}, \mathrm{B}$ and $\mathrm{C}$. The reliability index is approximately $\beta \approx 3.9$ (state $\mathrm{A}$ ) for reinforcement ratios up to $\rho_{1} \approx 2.0 \%$ o. Then, the reliability index decreases approximately linearly until it reaches its minimum of $\beta \approx 2.9$ (state B) for a reinforcement ratio of approximately $\rho_{1} \approx 4.75 \%$ o. Afterwards, the reliability index slightly increases again (state $C$ ).
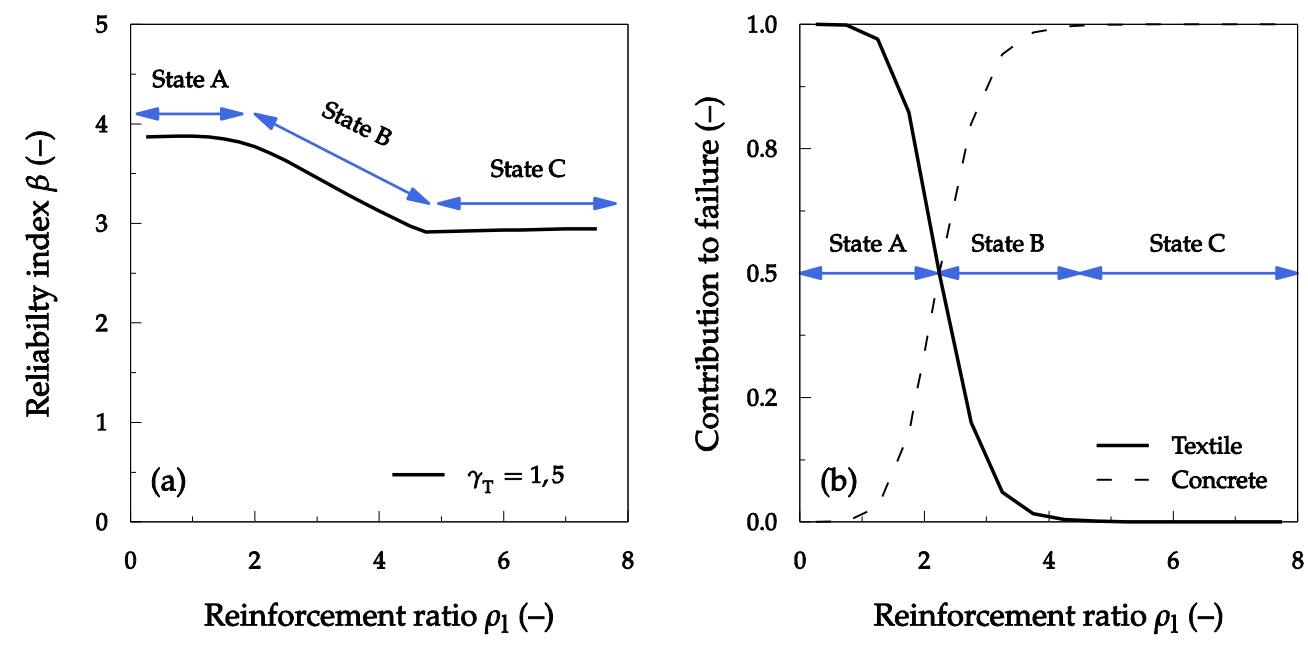

Figure 7. Results of the parametric studies: (a) reliability index; (b) contribution to failure.

In state $\mathrm{A}$, the textile reinforcement governs the bending load capacity. Both parameters- the design value of the textile tensile strength $f_{\mathrm{td}}$ in the ultimate limit state and the textile stress $f_{\mathrm{t}}^{*}$ at 
the design point $x^{*}$ - govern the load-bearing capacity. In state $\mathrm{C}$, the reverse occurs, and the design concrete compressive strength $f_{\mathrm{cd}}$ in the ultimate limit state and the concrete compressive stress $f_{\mathrm{c}}{ }^{*}$ at the design point $x^{*}$ govern the load-bearing capacity. In state B, reflecting a textile failure, the design value of the textile tensile strength $f_{\mathrm{td}}$ in the ultimate limit state governs the load-bearing capacity. However, the results show that concrete failure occurs with the same longitudinal reinforcement ratio. The reason for this is that the tensile strength of the reinforcement is underestimated in the calculation model due to the applied partial safety factor $\gamma_{\mathrm{T}}$ in the ultimate limit state. In fact, the load-bearing capacity of the textiles is higher than the capacity of the concrete in state B. As the reinforcement ratio increases, the reversed conditions occur at failure load. The probability that a concrete failure occurs increases.

In general, at any reinforcement ratio $\rho_{1}$, the cause of failure can be the concrete and the reinforcement. However, at low $\rho_{1}$ values, the current concrete compressive strength is not likely to be fully used. In this case, the textile reinforcement is governing in the event of failure. At high $\rho_{1}$ values, reversed conditions occur, and the concrete strength is usually critical for a failure event.

In the following sections, the influence of selected parameters on the probability of failure is presented. In order to illustrate this influence, only the parameter being examined varies in each case. A detailed description of the calculations can be found in [9].

\subsection{Comparison of the Methods for Determining Reliability}

To show the equivalence of the methods FORM, MC and MC-IS, the calculated probabilities of failure (or reliability indices $\beta$ ) are compared for an AR-glass and a carbon textile reinforcement $\left(\gamma_{\mathrm{T}}=1.5\right.$ ) (Figure 8). Comparable reliability indices are obtained regardless of the calculation method used.
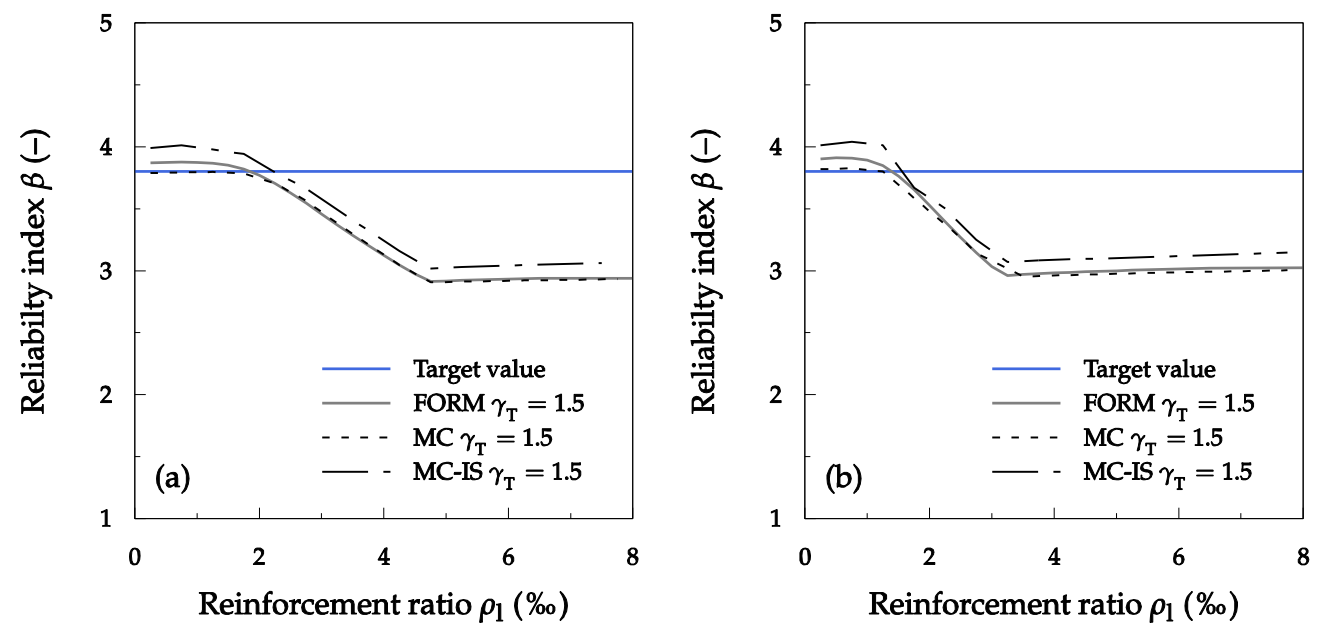

Figure 8. Reliability indices calculated according to FORM, Monte Carlo method (MC) and Monte Carlo method with importance sampling (MC-IS) considering an effective depth of $d=15 \mathrm{~mm}$ : (a) AR-glass; (b) carbon.

The reliability indices determined according to the MC and MC-IS are constantly about $\Delta \beta \approx 0.1$ higher or lower over the entire range of the curve than when using the FORM. This difference was also observed in the example calculations of Rackwitz [29]. In the calculations carried out by Ricker [19], the differences were partly $\Delta \beta \approx 0.4$. It can be assumed that with the MC, the probabilities of failure can be more accurately calculated if a sufficient amount of simulations are conducted. However, since in the example addressed in this study the differences are small, they can be neglected. Based on these considerations, a FORM analysis is sufficient to determine the reliability of textile-reinforced concrete components subject to bending loads. For this reason, only the results of the parametric studies determined with the FORM are shown below. 


\subsection{Influence of the Stress-Strain Curve of Concrete}

The influence of the assumed concrete stress-strain curve on the reliability index is shown in Figure 9. The three states A, B and C can be observed in both approaches. In state A, it can be seen that the reliability indices $\beta$ are similar for the same $\gamma_{T}$ values, independently of the material model used for the concrete. A small difference is observed in state C. In this case, the safety level is slightly higher when a linear stress-strain curve is applied than when a rectangular stress block is applied. The governing difference is the range of concrete failure (state C), which in the case of a rectangular stress-strain curve starts at a higher reinforcement ratio. This is due to the larger resulting concrete compressive zone force $F_{\mathrm{c}}$, which occurs when a rectangular stress block is considered. As a consequence, concrete failure only occurs for high reinforcement ratios (see [23]).
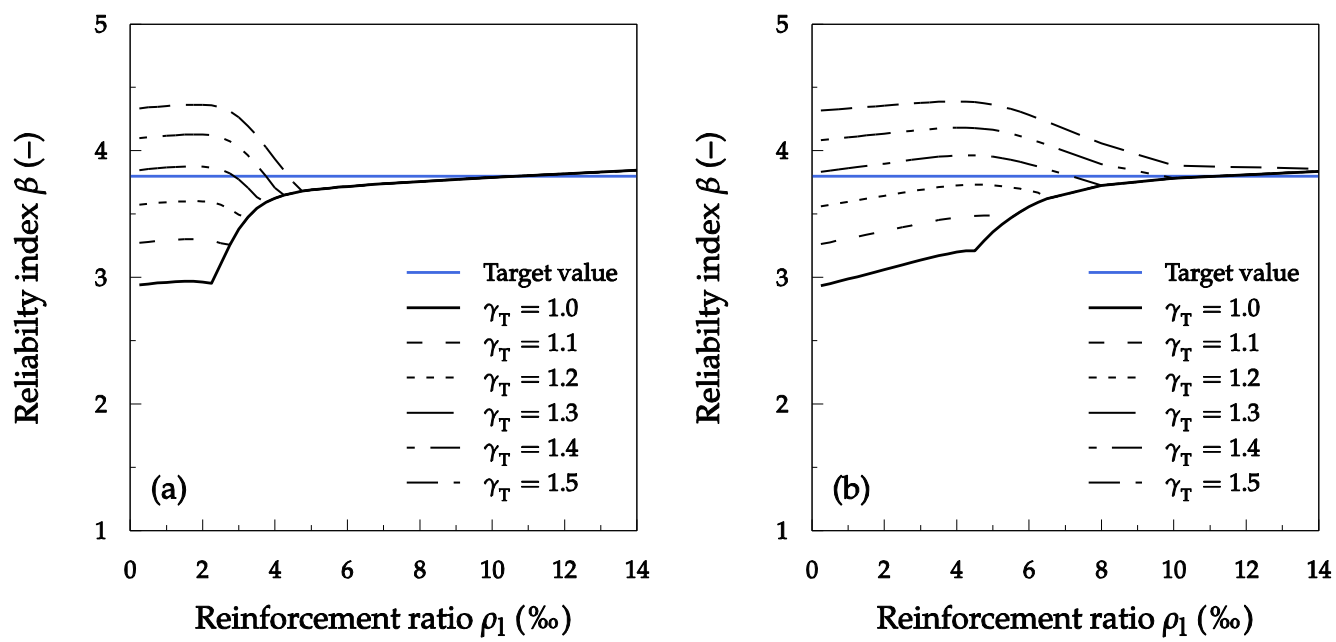

Figure 9. Reliability indices calculated according to FORM considering an effective depth of $d=60 \mathrm{~mm}$ :

(a) linear $\sigma-\varepsilon$ diagram; (b) rectangular $\sigma-\varepsilon$ diagram.

The results show that the calculated bending capacities of the concrete can be sufficiently approximated by a linear and by a rectangular stress-strain curve [23]. Thus, in the parametric studies shown below, only the results determined under the assumption of a linear stress-strain curve for the concrete are presented.

\subsection{Influence of the Reinforcement Type}

The influence of the reinforcement type on the reliability index was investigated using specimens reinforced with AR-glass and a carbon textile reinforcement. In the calculations, the type of reinforcement was taken into account by different parameters for the tensile strength $f_{\mathrm{t}}$ and the Young's modulus $E_{\mathrm{t}}$. The results are shown in Figure 10.

According to Figure 10, the shapes of the reliability index curves are similar, independently of the reinforcement type. Only the transition from state A to B occurs for the AR-glass textile reinforcement at a higher reinforcement ratio, which is due to the different tensile strengths. In comparison to AR-glass textile reinforcement, carbon textile reinforcement can withstand significantly larger tensile force $F_{\mathrm{t}}$ with the same reinforcement ratios $\rho_{1}$ presupposed. Thus, to fulfil the equilibrium of forces with the same reinforcement ratio, a greater concrete pressure zone force $F_{\mathrm{c}}$ is required for carbon textile reinforcement than for AR-glass textile reinforcement. Since the same concrete compressive strength $f_{\mathrm{c}}$ is assumed for both types of reinforcement, concrete failure occurs in specimens with carbon reinforcement at a lower reinforcement ratio. 

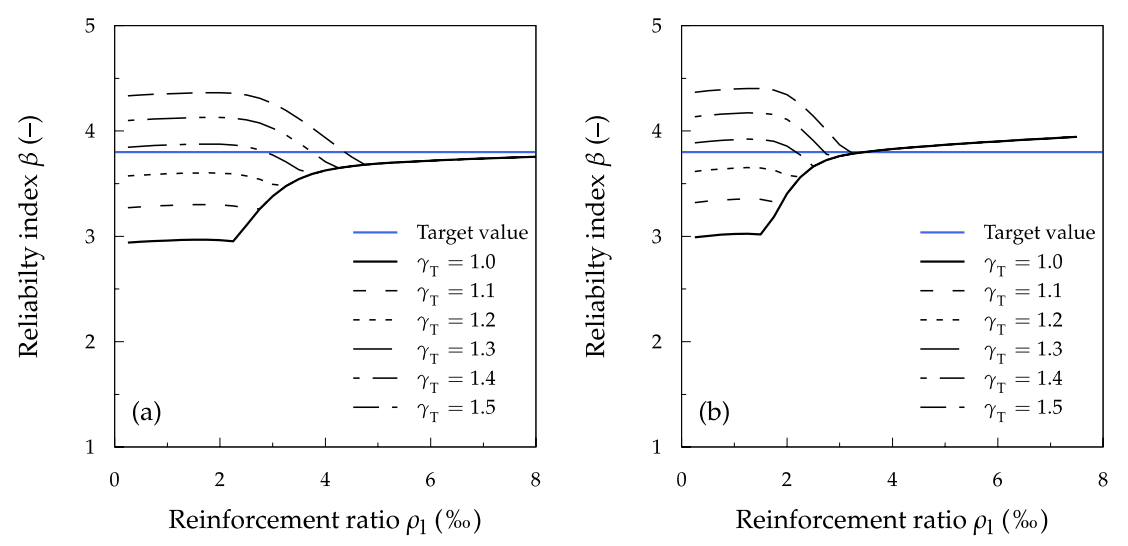

Figure 10. Reliability indices calculated according to FORM considering an effective depth of $d=60$ mm: (a) AR-glass textiles; (b) carbon textiles.

In state $\mathrm{A}$, a partial safety factor $\gamma_{\mathrm{T}}$ equal to 1.3 for both types of reinforcement and a partial safety factor $\gamma_{C}$ equal to 1.5 for the concrete are sufficient to achieve the desired safety level of $\beta_{\text {target }}$ equal to 3.8. For a reinforcement ratio of $\rho_{1} \approx 3.5 \%$, the reliability index calculated goes below the threshold of 3.8 by about $\Delta \beta=0.1$. Due to the governing concrete failure, the safety level can then no longer be significantly increased by applying a larger partial safety factor $\gamma_{\mathrm{T}}$ for the textile reinforcement. From the authors' point of view, the undercutting of the target index of 0.1 is still acceptable. In state $\mathrm{C}$, the reliability index is initially slightly below the target value of $\beta$ equal to 3.8; however, the value increases for a higher reinforcement ratio. As a result, the calculated reliability indices rapidly reach the threshold value of 3.8. The assumed partial safety factor for the textile reinforcement $\left(1.0 \leq \gamma_{\mathrm{T}} \leq\right.$ 1.5) has no influence on the reliability indices calculated, as the different curves in state $C$ have the same value due to the governing concrete failure.

The sensitivity factors for each parameter depending on the reinforcement ratio $\rho_{1}$ are shown in Figure 11. These factors describe the influence of the different parameters on the reliability index $\beta$. The sensitivity factors are similar for both types of textiles. In all the three states, it is noticeable that the live load $q$ has the greatest influence on the reliability index due to its wide scattering. At the same time, it can be observed that the textile tensile strength $f_{\mathrm{t}}$ is a governing factor in state $\mathrm{A}$, while the most influential factor in state $C$ is the concrete compressive strength $f_{\mathrm{c}}$. In total, the sensitivity factor of the impact side $\alpha_{\mathrm{E}}$, which is composed by the sensitivity factor for the model uncertainty of the loading models $\theta_{\mathrm{E}}$ and the sensitivity factors for the dead load $g$ and the live load $q$, has a value of approximately 0.9 in state A and approximately 0.8 in state C. Hence, these values exceed the recommendation in EN 1990 (EC0) [21], where $\alpha_{\mathrm{E}, \mathrm{EC} 0}$ is equal to 0.7. This value is proposed in the code for semi-probabilistic calculations, in which the resistance side can be considered decoupled from the impact side by specifying corresponding constant weighting factors.

On the resistance side, $\alpha_{\mathrm{R}}$ is approximately 0.5 (state $\mathrm{A}$ ) or $\alpha_{\mathrm{R}}$ is approximately 0.6 (state $\mathrm{C}$ ). These values are slightly lower than the recommended values in EN 1990 [21] where $\alpha_{\mathrm{R}, \mathrm{EC} 0}$ is equal to 0.8 . However, the values in the code for $\alpha_{\mathrm{E}, \mathrm{EC} 0}$ and $\alpha_{\mathrm{R}, \mathrm{EC} 0}$ can never be achieved in a fully probabilistic calculation since the squared sum of $\alpha_{\mathrm{E}, \mathrm{EC} 0}{ }^{2}+\alpha_{\mathrm{R}, \mathrm{EC} 0}{ }^{2}$ is 1.13, which is higher than 1.0. Thus, for certain conditions, the sensitivity factors specified in the code for a semi-probabilistic calculation are on the safe side.

The calculations presented in this section show that the same partial safety factor for textile reinforcement is needed for both AR-glass and carbon textiles to achieve the required safety level. Therefore, the type of reinforcement has almost no influence on $\gamma_{\mathrm{T}}$. This result was observed for all the parameter variations [9]. 


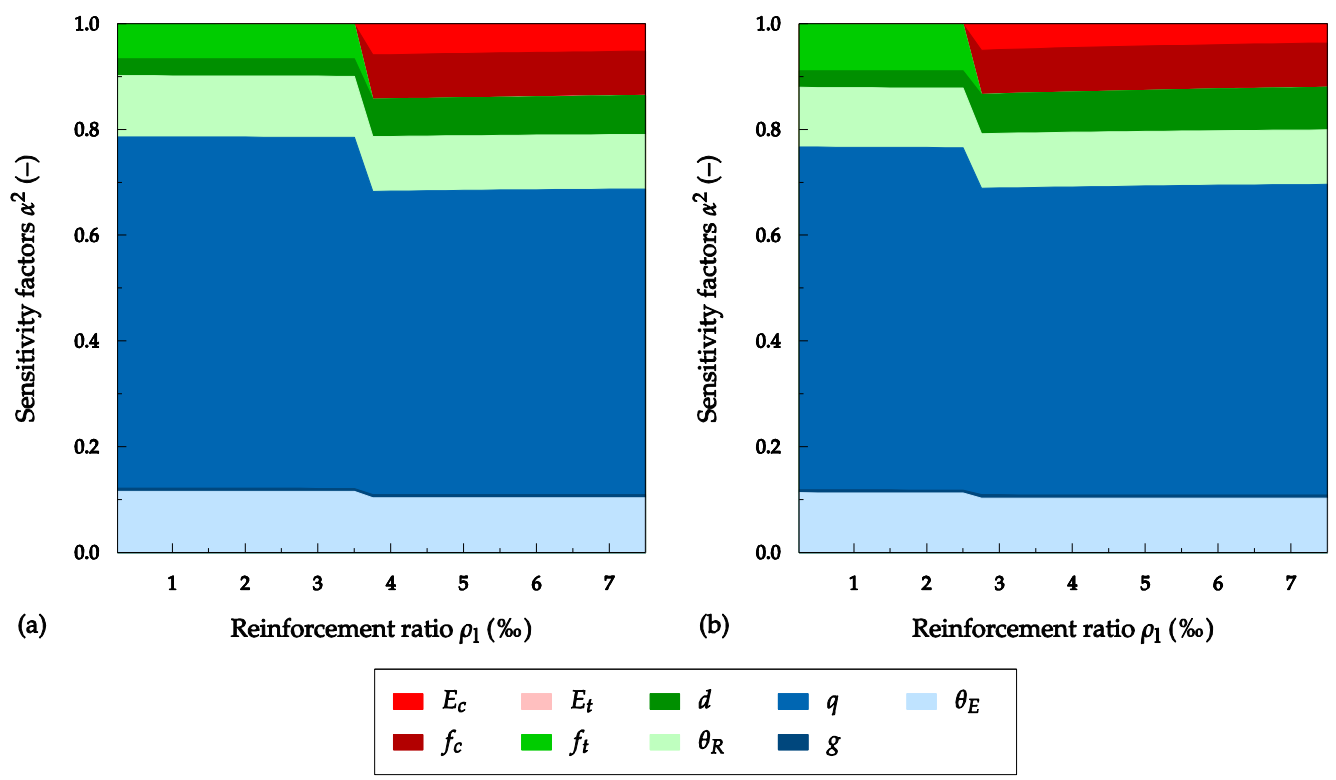

Figure 11. Sensitivity factors calculated for $\gamma_{\mathrm{T}}=1.3$ according to FORM: (a) AR-glass textiles; (b) carbon textiles.

\subsection{Influence of the Effective Depthd}

The influence of the effective depth $d$ on the reliability index $\beta$ was investigated for a carbon textile reinforcement with effective depths of $d=15 \mathrm{~mm}$ and $d=60 \mathrm{~mm}$ (Figures 12 and 13).
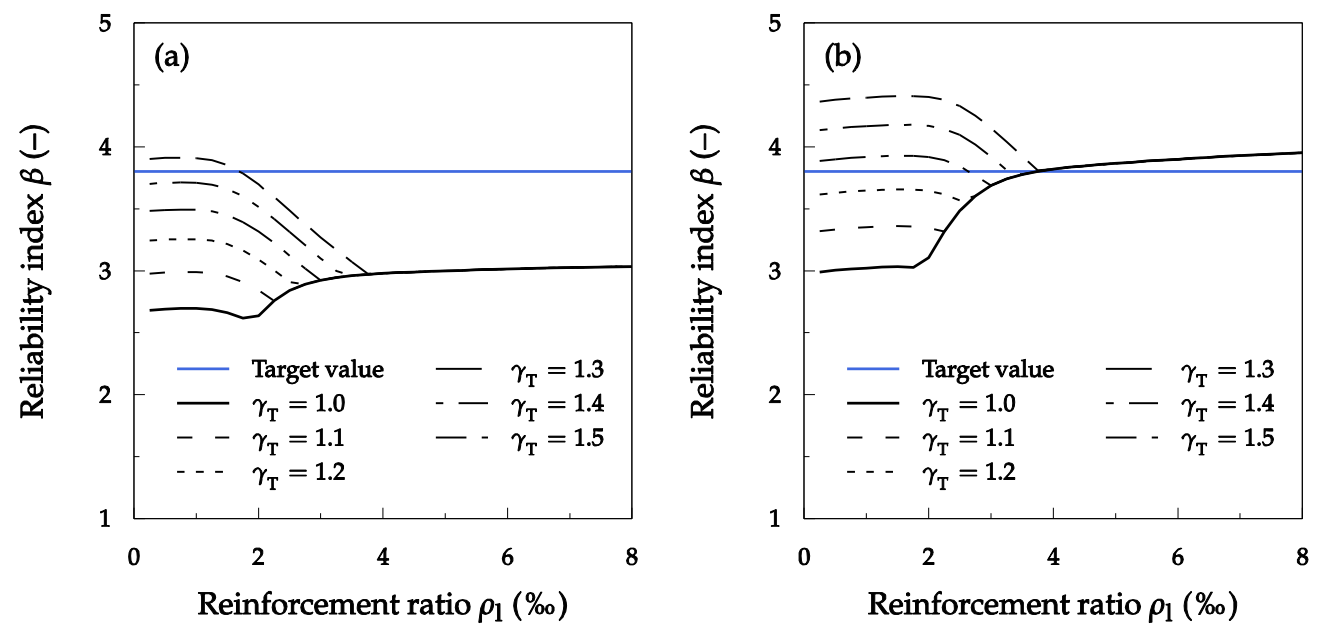

Figure 12. Reliability indices calculated according to FORM: (a) effective depth $d=15 \mathrm{~mm}$; (b) effective depth $d=60 \mathrm{~mm}$.

The effective depth $d$ has an influence on the progression of the reliability index curves both in state $\mathrm{A}$ and in state $\mathrm{C}$. Subsequently, the effective depth $d$ is $60 \mathrm{~mm}$; to achieve an appropriate safety level, it is sufficient to apply a partial safety factor $\gamma_{\mathrm{T}}$ equal to 1.3 and a partial safety factor $\gamma_{\mathrm{C}}$ equal to 1.5 in states $\mathrm{A}$ and $\mathrm{C}$, respectively. For the smallest effective depth, i.e., $d=15 \mathrm{~mm}$, and for the selected partial safety factors $\gamma_{\mathrm{T}}$ equal to 1.3 and $\gamma_{\mathrm{C}}$ equal to 1.5 , the required reliability index $\beta_{\text {target }}$ of 3.8 cannot be ensured. These results can be explained by the large influence of the effective depth $d$ scattering on the reliability index $\beta$, which is proven by the sensitivity factors (Figure 13). These observations are valid for the application of a linear or a rectangular stress-strain curve for the concrete analysis [9]. 


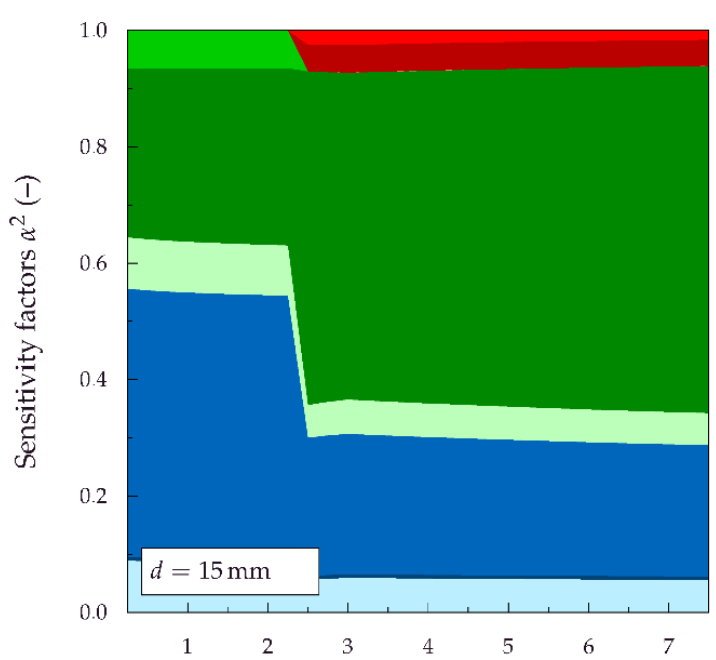

(a)

Reinforcement ratio $\rho_{1}(\%)$

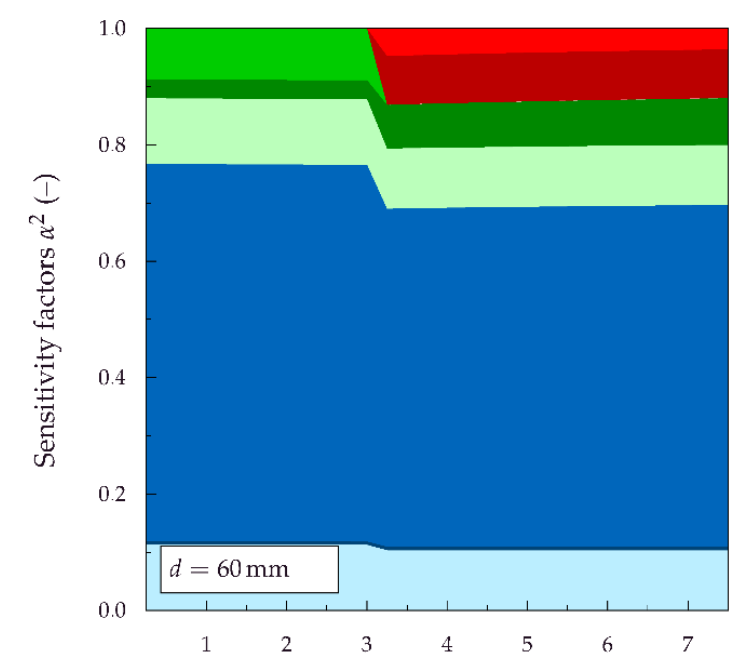

(b)

Reinforcement ratio $\rho_{1}(\%)$

$\begin{array}{|llllll|}E_{c} & E_{t} & - & d & q & \theta_{E} \\ f_{c} & f_{t} & \theta_{R} & \square & \end{array}$

Figure 13. Sensitivity factors calculated for $\gamma_{\mathrm{T}}=1.3$ according to FORM: (a) effective depth $d=15 \mathrm{~mm}$; (b) effective depth $d=60 \mathrm{~mm}$.

In the case of very thin structural members, even a slight deviation of the reinforcement from the correct position can lead to a large reduction of the bending capacity. For this reason, in order to ensure a sufficient safety level with a constant partial safety factor $\gamma_{\mathrm{T}}$ independent of the effective depth, the authors recommend using a reduction factor for small effective depth, taken from the old German code DIN 1045(88) [30]. DIN 1045(88) proposes to increase the internal forces with a factor of $15 /(d+8)$ for structural members with effective depths smaller than $70 \mathrm{~mm}$. This approach can be adopted for thin textile-reinforced members. Since the probabilistic calculations show that the required safety level can be ensured for effective depths $d$ greater than $60 \mathrm{~mm}$ (Figure 12a), it is sufficient to apply a reduction for effective depths $d \leq 60 \mathrm{~mm}$. With Equations (17) and (18), an effective depth $d_{\text {eff }}$ can be determined, which can be used to calculate the required flexural textile reinforcement.

$$
\begin{gathered}
\text { for } d \leq 60 \mathrm{~mm} d_{e f f}=\frac{d-4}{0.95}(\mathrm{~d} \text { in } \mathrm{mm}) \\
\text { for } d>60 \mathrm{~mm} d_{e f f}=d
\end{gathered}
$$

Figure 14 shows the influence of $d$ and $d_{\text {eff }}$ on the reliability index. The required safety level is ensured with the effective depth $d_{\text {eff }}$ for the three states A, B and C. In contrast, in the calculation of the reliability indices, the threshold $\beta_{\text {target }}$ of 3.8 cannot be achieved when the effective depth $d$ is not reduced. Consequently, the required safety level can be ensured while retaining the common partial safety factor for concrete $\gamma_{C}$ equal to 1.5 . 


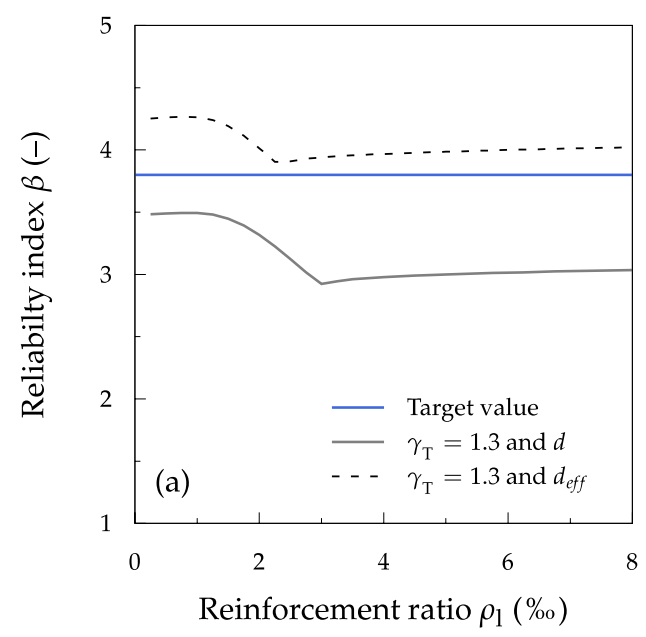

Figure 14. Reliability indices calculated according to FORM for the effective depth $d$ and the reduced effective depth $d_{\text {red }}$.

\section{Summary and Proposal for the Partial Safety Factor for Textile Reinforcement $\gamma_{T}$}

The probabilistic calculations show that the safety level depends significantly on the reinforcement ratio and on the effective depth. These two parameters primarily influence the required partial safety factors for textile reinforcement $\gamma_{\mathrm{T}}$ and for concrete $\gamma_{\mathrm{C}}$. The remaining parameters-tensile strength of the textile reinforcement, concrete compressive strength, long-term durability factor $\alpha_{\mathrm{t}}$ and the ratio of dead to live loads-seem to have insignificant influence on the probability of failure and, therefore, on the required partial safety factors. As an advantage, this means that the proposed safety factor $\gamma_{\mathrm{T}}$ can generally be derived for textiles impregnated with epoxy resin.

Figure 15 shows the reliability indices determined in the parametric studies as a function of the reinforcement ratio and the effective depth. Figure 15a shows the reliability indices calculated with a partial safety factor $\gamma_{\mathrm{T}}$ equal to 1.3 for the textile reinforcement and $\gamma_{\mathrm{C}}$ equal to 1.5 for the concrete. In the area of the black contour lines, the estimated reliability indices are larger than the threshold of 3.8; in the area of the red contour lines, the estimated reliability indices are smaller. It can be seen that especially thinner members $(d<60 \mathrm{~mm})$ are within this area of insufficient safety level. Figure 15b shows the results achieved under the assumption of a reduced effective depth $d_{\text {eff }}$ for thinner members. The red contour lines, indicating reliability indices below the threshold of 3.8, are significantly diminished. The target reliability index $\beta_{\text {target }}$ of 3.8 is now only undercut in a small area, which is characterized by a reinforcement level of about $4 \%$ ond an effective depth of $75 \mathrm{~mm}$. The reliability indices within this area have values of approximately 3.7. From the authors' point of view, these results are acceptable, because the deviation from the threshold of 0.1 lies within the range of the calculation methods applied. For example, the MC-IS results in reliability indices about 0.1 higher than the FORM used; thus, a sufficiently high safety level can be assumed. 

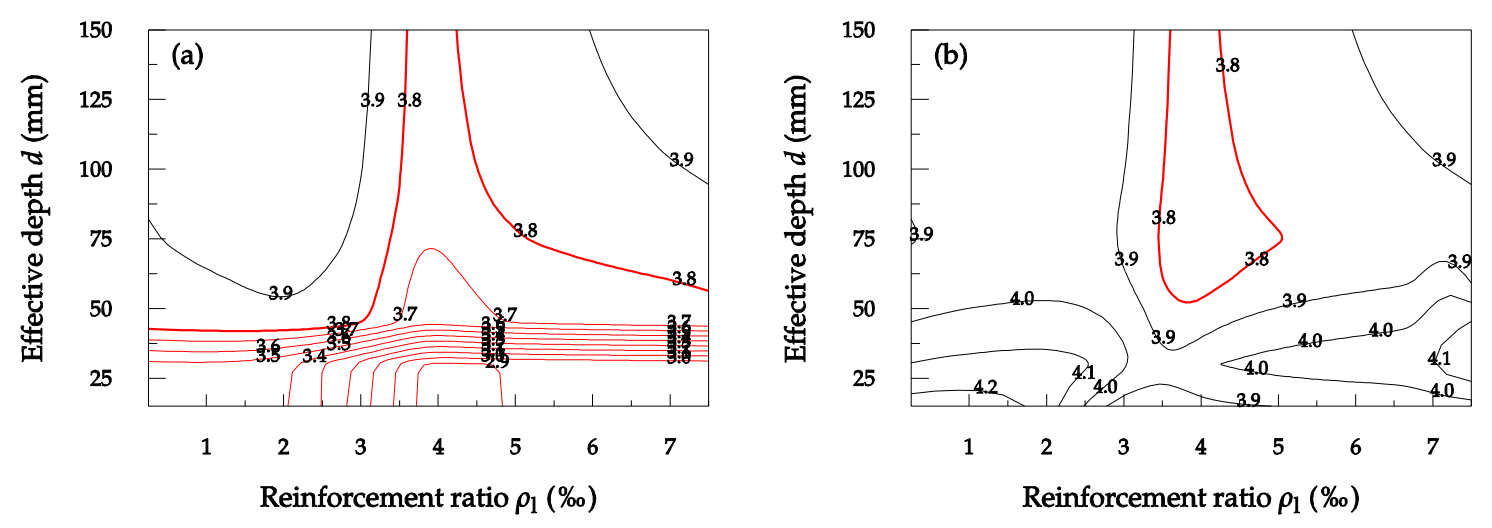

Figure 15. Reliability indices for (a) $\gamma_{\mathrm{T}}=1.3$ and $\gamma_{C}=1.5 ;(\mathbf{b}) \gamma_{\mathrm{T}}=1.3, \gamma_{\mathrm{C}}=1.5$ and deff.

Based on the results presented, a value of $\gamma_{\mathrm{T}}$ equal to 1.3 is proposed as a partial safety factor for epoxy resin impregnated textile reinforcement. The partial safety factor $\gamma C$ for the concrete can be assumed equal to 1.5 , which is the same value normally used for the design of steel-reinforced concrete constructions. For thin textile-reinforced structural members with an effective depth $d \leq 60 \mathrm{~mm}$, it is recommended to apply a reduced effective depth $d_{\text {eff }}$.

This paper discussed the safety concept for textile-reinforced concrete structures with bending load. For a general design, the shear capacity has also to be considered. The described probabilistic procedure can used with the existing design models [31-36] to derive appropriate partial safety factors for other failure modes.

Author Contributions: Conceptualization, S.R., M.R. and J.H.; methodology, S.R. and M.R.; writing-original draft preparation, S.R.; writing-review and editing, M.R.; visualization, S.R. and M.R.; supervision, M.R. and J.H.; funding acquisition, J.H. All authors have read and agreed to the published version of the manuscript.

Funding: This research was funded by BMBF, grant number 03ZZ0321C.

Acknowledgments: The authors give their thanks to solidian $\mathrm{GmbH}$ for donation of the carbon grid reinforcement used for the experiments. The authors are particularly thankful for the financial support by the BMBF during the project C3 V1.2.

Conflicts of Interest: The authors declare no conflict of interest. The founding sponsors had no role in the design of the study; in the collection, analyses, or interpretation of data; in the writing of the manuscript; or in the decision to publish the results.

\section{References}

1. Kromoser, B.; Preinstorfer, P.; Kollegger, J. Building lightweight structures with carbon-fiber-reinforced polymerreinforced ultra-high-performance concrete: Research approach, construction materials, and conceptual design of three building components. Struct. Concr. 2019, 20, 730-744. [CrossRef]

2. Schumann, A.; Michler, H.; Schladitz, F.; Curbach, M. Parking slabs made of carbon reinforced concrete. Struct. Concr. 2018, 19, 647-655. [CrossRef]

3. Scholzen, A.; Chudoba, R.; Hegger, J. Thin-walled shell structures made of textile-reinforced concrete: Part I. Struct. Concr. 2015, 16, 106-114. [CrossRef]

4. Bielak, J.; Schmidt, M.; Hegger, J.; Jesse, F. Structural Behavior of Large-Scale I-Beams with Combined Textile and CFRP Reinforcement. Appl. Sci. 2020, 10, 4625. [CrossRef]

5. Adam, V.; Bielak, J.; Dommes, C.; Will, N.; Hegger, J. Flexural and Shear Tests on Reinforced Concrete Bridge Deck Slab Segments with a Textile-Reinforced Concrete Strengthening Layer. Materials 2020, 13, 4210. [CrossRef]

6. JCSS. Probabilistic Model Code. Joint Committee for Structural Safety. 2001. Available online: http: //www.jcss.byg.dtu.dk (accessed on 1 June 2018).

7. Voigt, J. Beitrag zur Bestimmung der Tragfähigkeit bestehender Stahlbetonkonstruktionen auf Grundlage der Systemzuverlässigkeit. Ph.D. Thesis, University of Siegen, Siegen, Germany, 28 February 2014.

8. Maple. Maplesoft; A division of Waterloo Maple Inc.: Waterloo, ON, Canada, 2017. 
9. Rempel, S. Zur Zuverlässigkeit der Bemessung von biegebeanspruchten Betonbauteilen mit textiler Bewehrung. Ph.D. Thesis, RWTH-Aachen University, Aachen, Germany, 23 April 2018.

10. Rempel, S.; Ricker, M.; Hegger, J. Zuverlässigkeitsanalyse für biegebeanspruchte Textilbetonbauteile. Beton Stahlbetonbau 2020, 115, 697-709. [CrossRef]

11. Hegger, J.; Kulas, C.; Horstmann, M. Spatial Textile Reinforcement Structures for Ventilated and Sandwich Facade Elements. Adv. Struct. Eng. 2012, 15, 665-675. [CrossRef]

12. Shams, A.; Horstmann, M.; Hegger, J. Experimental investigations on Textile-Reinforced Concrete (TRC) sandwich sections. Compos. Struct. 2014, 118, 643-653. [CrossRef]

13. Stark, A.; Kueres, D.; Hegger, J. Sandwichelemente mit UHPC-Deckschichten und geschäumten PUR-Kernschichten. Beton Stahlbetonbau 2016, 111, 816-827. [CrossRef]

14. Ehlig, D.; Schladitz, F.; Frenzel, M.; Curbach, M. Textilbeton -Ausgeführte Projekte im Überblick. Beton Stahlbetonbau 2012, 107, 777-785. [CrossRef]

15. Hegger, J.; Kulas, C.; Raupach, M.; Büttner, T. Tragverhalten und Dauerhaftigkeit einer schlanken Textilbetonbrücke-Eine $97 \mathrm{~m}$ lange Fußgängerbrücke mit einer Bewehrung aus AR-Glasfilamenten. Beton Stahlbetonbau 2011, 106, 72-80. [CrossRef]

16. Hegger, J.; Goralski, C.; Kulas, C. Schlanke Fußgängerbrücke aus Textilbeton—Sechsfeldrige Fußgängerbrücke mit einer Gesamtlänge von 97 m. Beton Stahlbetonbau 2011, 106, 64-71. [CrossRef]

17. Helbig, T.; Rempel, S.; Unterer, K.; Kulas, C.; Hegger, J. Fuß- und Radwegbrücke aus Carbonbeton in Albstadt-Ebingen. Die weltweit erste ausschließlich carbonfaserbewehrte Betonbrücke. Beton Stahlbetonbau 2016, 111, 676-685. [CrossRef]

18. Curbach, M.; Graf, W.; Jesse, D.; Sickert, J.-U.; Weiland, S. Segmentbrücke aus textilbewehrtem Beton-Konstruktion, Fertigung, numerische Berechnung. Beton Stahlbetonbau 2007, 102, 342-352. [CrossRef]

19. Ricker, M. Zur Zuverlässigkeit der Bemessung gegen Durchstanzen bei Einzelfundamenten. Ph.D. Thesis, RWTH-Aachen University, Aachen, Germany, 23 November 2009.

20. Fischer, A. Bestimmung modifizierter Teilsicherheitsbeiwerte zur semiprobabilistischen Bemessung von Stahlbetonkonstruktionen im Bestand. Ph.D. Thesis, University of Kaiserslautern, Kaiserslautern, Germany, 5 November 2010.

21. DIN EN 1990:2002 + A1:2005 + A1:2005/AC:2010. Eurocode: Basis of Structural Design. CEN European Committee for Standardization. 2002. Available online: https://shop.standards.ie/preview/98706582598.pdf? sku=861303_SAIG_NSAI_NSAI_2049116 (accessed on 18 October 2020).

22. Rempel, S.; Ricker, M. Ermittlung der Materialkennwerte der Bewehrung für die Bemessung von textilbewehrten Bauteilen. Bauingenieur 2017, 92, 280-288.

23. Rempel, S.; Ricker, M.; Hegger, J. Biegebemessungsmodell mit einer geschlossenen und iterativen Lösung für Textilbetonbauteilen. Beton Stahlbeton 2019, 115, 218-230. [CrossRef]

24. DIN EN 1992-1-1:2004 + AC:2010. In Eurocode 2: Design of Concrete Structures_Part 1-1: General Rules and Rules for Buildings; Beuth: Berlin, Germany, 2011.

25. Spelter, A.; Bergmann, S.; Bielak, J.; Hegger, J. Long-Term Durability of Carbon-Reinforced Concrete: An Overview and Experimental Investigations. Appl. Sci. 2019, 9, 1651. [CrossRef]

26. Ditlevsen, O.; Madsen, H. Structural Reliability Methods, 1st ed.; Wiley: New York, NY, USA, 1996.

27. Six, M. Sicherheitskonzept für nichtlineare Traglastverfahren im Betonbau. In Heftreihe des Deutschen Ausschuss für Stahlbeton, 1st ed.; Beuth: Berlin, Germany, 2003; Volume 534.

28. Melchers, R.E.; Beck, A.T. Structural Reliability Analysis and Prediction; John Wiley \& Sons: Hoboken, NJ, USA, 2018.

29. Rackwitz, R. Zuverlässigkeit von Tragwerken. In Handbuch für Bauingenieure; Zilch, K., Diederichs, C.J., Katzenbach, R., Eds.; Springer: Berlin, Germany, 2001.

30. DIN 1045 Juli 1988. In Beton Stahlbeton; Bemessung und Ausführung: Berlin, Germany, 1988.

31. Bielak, J.; Spelter, A.; Will, N.; Claßen, M. Verankerungsverhalten textiler Bewehrungen in dünnen Betonbauteilen. Beton Stahlbetonbau 2018, 113, 515-524. [CrossRef]

32. Bielak, J.; Adam, V.; Hegger, J.; Classen, M. Shear capacity of textile-reinforced concrete slabs without shear reinforcement. Appl. Sci. 2019, 9, 1382. [CrossRef]

33. Stark, A.; Classen, M.; Knorrek, C.; Camps, B.; Hegger, J. Sandwich panels with folded plate and doubly curved UHPFRC facings. Struct. Concr. 2018, 19, 1851-1861. [CrossRef] 
34. Stark, A.; Classen, M.; Hegger, J. Bond behaviour of CFRP tendons in UHPFRC. Eng. Struct. 2019, 178, 148-161. [CrossRef]

35. Herbrand, M.; Adam, V.; Classen, M.; Kueres, D.; Hegger, J. Strengthening of existing bridge structures for shear and bending with carbon textile-reinforced mortar. Materials 2017, 10, 1099. [CrossRef] [PubMed]

36. Classen, M. Shear Crack Propagation Theory (SCPT)-The mechanical solution to the riddle of shear in RC members without shear reinforcement. Eng. Struct. 2020, 210, 110207. [CrossRef]

Publisher's Note: MDPI stays neutral with regard to jurisdictional claims in published maps and institutional affiliations.

(C) 2020 by the authors. Licensee MDPI, Basel, Switzerland. This article is an open access article distributed under the terms and conditions of the Creative Commons Attribution (CC BY) license (http://creativecommons.org/licenses/by/4.0/). 